\title{
Grupo profissional e mercado de trabalho do jornalismo*
}

Denis Ruellan**

Quer abordem o jornalismo através dos seus fundamentos sociológicos, da sua relação com o espaço do público, da deontologia, da ambivalência do projecto económico, dos procedimentos de aprendizagem e de integração de valores, das modalidades de produção..., os recentes trabalhos de investigação sublinharam que, como outras actividades, o jornalismo é mais do que uma actividade: é um grupo. É a sede de uma formação social de trabalhadores, importante, activa e relevante, independentemente das estruturas clássicas, sindicais, empresariais, associativas. Esses trabalhadores situam-se numa dimensão colectiva, constituindo, por isso, uma formação social cujas formas estão por definir, mas que podemos, desde logo, qualificar como "grupo profissional" a fim de evitar o termo "profissão", que pensamos estar muito codificado.

O nosso propósito de investigação é fazer um percurso antropológico que visa compreender como e porquê os actores sociais construíram e tornaram visíveis este "grupo", ao qual deram existência e legitimidade através de um processo de negociação, de organizações, de representações e de dispositivos jurídicos. Que "grupo profissional" será este, hoje tão real no espírito da sociedade, tão visível no debate social, e que há um século, talvez nem tanto, era ainda desconhecido?

A aproximação que propomos conduz-nos a ver no mercado de trabalho (o seu controlo, o seu fechamento) o motivo fundamental da constituição - a razão de ser dos grupos profissionais, bem como o seu instrumento:

- os grupos constituem-se para controlar o mercado de emprego (ou seja, uma parte da riqueza);

- os grupos constituem-se através do mercado, nomeadamente a partir de um dos seus segmentos.

Invocando o caso exemplar dos jornalistas, este artigo debruça-se sobre as bases conceptuais e metodológicas a partir das quais o estudo dos grupos profissionais se pode enraizar.

\section{Ideal-tipo e indeterminação}

\footnotetext{
* ( ) Réseaux, n. ${ }^{\circ} 81$ CNET - 1997. Autorização expressa de tradução concedida pelo editor.

** Director do Departamento de Informação-Comunicação do IUT da Universidade de Rennes 1 (França).
} 
Pensar os jornalistas como um "grupo profissional” consiste, antes de tudo, em escapar a uma representação ideal-típica das "profissões”, herdada da corrente funcionalista. Com efeito, esta tende a apagar a dimensão histórica dos grupos profissionais, o processo de formação das estruturas e das organizações, o que usualmente se designa como profissionalização. De algum modo, essa corrente estipula que as profissões valem por si e ignora que elas possam ser construções, enunciativas e organizacionais, resultantes de rivalidades colectivas, reunindo interesses individuais e, no fim de contas, procurando o domínio da representação do mundo social ou de parcelas deste.

Hughes (1971) propunha que se corrigissem as argumentações dos grupos profissionais que haviam alcançado um grau elevado de reconhecimento pela acção de legitimação dos defensores científicos da escola estrutural-funcionalista e apelava para que se distinguissem os fundamentos da organização profissional dos seus modos de legitimação. Os estudos que seguiam esta linha procuravam compreender porquê e como certas profissões - dispondo geralmente de um estatuto jurídico derrogatório face ao direito comum, muito cobiçado na medida em que era construtor e legitimador de privilégios - haviam alcançado os seus objectivos (Paradeise, 1988). Situação que os jornalistas franceses conheciam desde a lei de 1935 e que se estende igualmente aos seus colegas da maior parte dos países do mundo. Um inquérito do Bureau Internationale $d u$ Travail, realizado em 1928, já havia demonstrado que os dispositivos jurídicos especiais eram correntes, nomeadamente em Itália, Alemanha, Grã-Bretanha, Áustria e que os contratos de trabalho colectivos haviam sido assinados na Austrália, Espanha, Roménia, Estónia, Letónia, Suécia, Suíça, Hungria e Checoslováquia.

Renunciar ao ideal-tipo leva-nos assim a enveredar pela imprecisão, pela variação e pela fluidez dos grupos. Optando por uma abordagem interaccionista, Bucher e Strauss propuseram que se considerassem os grupos profissionais não como entidades solidificadas, mas como grupos permanentemente em movimento, porque constituídos por "amálgamas distendidas de segmentos que perseguem objectivos diferentes de maneiras diferentes, mantendo-se, de forma mais ou menos frágil, sob uma denominação comum num período específico da história” (Bucher \& Strauss, 1961, cit. in Baszanger, 1990).

Esta proposta de trabalhar a fluidez foi seguida por H. (Becker, 1982, tradução de 1988, cit. in Baszanger, 1990); este refuta as classificações estanques e as distinções estritas, sugerindo, antes, a observação das estratégias distintivas dos actores, os factos, os valores, os signos que permitem aos indivíduos constituírem categorias, estabelecerem fronteiras e justificarem aceitações ou exclusões. Encontramos também esta aproximação em L. Boltansky (1982) que fala do "efeito dinâmico da fronteira” no seu estudo do grupo dos quadros: "Tal como a definição dos critérios de pertença ao grupo, o estabelecimento de fronteiras constitui, nas lutas, uma das tecnologias de objectivação de que se serve a acção política, sendo a institucionalização das fronteiras entre grupos um dos trunfos fundamentais das lutas políticas. As fronteiras entre grupos (como as fronteiras entre as nações) não são 'naturais'. Um grupo constituído por agregação ao redor de um pólo de atracção não tem outros limites para além da zona de incerteza onde se faz sentir, com uma força mais ou menos semelhante, a atracção de 
outros pólos. No entanto, resultado de um acto quase jurídico que objectiva e institucionaliza as relações sociais, as fronteiras contribuem para produzir diferenças 'objectivas' que justificam o seu traçado".

Em trabalhos anteriores, procurámos sublinhar as virtualidades da imprecisão. Falando do "profissionalismo do impreciso" (Ruellan, 1993), sustentámos a tese segundo a qual para cá dos discursos profissionalistas que tendiam a representar o jornalismo como um mundo estruturado e fundado numa competência clara e específica, seria necessário ver um universo fluido, com modos de gestão mal recortados e movediços, com uma cultura profissional marcada pela mestiçagem, proposta que seguimos invocando uma "vocação mestiça".

Acrescentámos que esta imprecisão não deveria ser encarada como uma disfunção, pois oferecia ao grupo capacidades de "amalgamagem", flexibilidade e redução de antagonismos absolutamente eficazes. Sublinhámos que este "flou” se aplicava não apenas às modalidades de produção, mas também marcava profundamente a identidade (jurídica e sociológica) e a qualificação (formação, competência). Decididamente seria toda a gestão do território profissional que era envolvida pela imprecisão e a fluidez.

\section{Historicidade}

Como afirma D. Segrestin (1985), “a função objectiva de qualquer organização profissional é precisamente a de absorver as crises e instalar a comunidade social num certo período de tempo". Nesta óptica, os grupos profissionais são estudados como “constructos históricos" (Lucas, 1994) que nascem, vivem, se reproduzem e desaparecem - moldados por condições diversas (políticas, económicas, tecnológicas, culturais) que lhes conferem a sua idiossincrasia. Apoiando-se nomeadamente nos exemplos de organização da medicina e do corpo de engenheiros do Estado, Sarfatti-Larson (1988) sublinha como pode o Estado ter um papel essencial no processo de "fechamento social”, favorecendo a institucionalização de estatutos derrogatórios ao direito comum. Esta intervenção pode situar-se no plano jurídico pela criação de constrangimentos que limitem o acesso ao exercício da profissão; ou pela via da formação (controlo dos cursos e diplomas).

Por vezes, o Estado encontra-se na origem desses processos institucionais. É o caso da França onde, tal como afirma John Weiss (Weiss, 1984, cit. in Sarfatti-Larson, 1988), o que parece mais comum, desde a época napoleónica, é a intervenção directa e voluntária do Estado na reestruturação das profissões e das classes sociais mediante o sistema de ensino e o restabelecimento dos corpos do Estado e das Ordens. Esta orientação é indubitavelmente tributária da tradição dirigista francesa.

A intervenção do Estado pode ser desencadeada pela necessidade de impor ordem nos conflitos sociais; os actores da profissionalização que interpelam o poder público procuram obter do Estado disposições com vista a criar, senão monopólios, pelo menos regimes controlados, de forma a fazer diminuir o nível de tensões. Trabalhos actuais relativos a profissões que apareceram recentemente (os psicólogos - Derosières \& Thévenot, 1988; os formadores - Primon, 1994) sublinham a vivacidade desta 
realidade de um Estado que se assume como árbitro. Foi assim que actuou no caso dos jornalistas que apelaram para o Parlamento, depois do insucesso de uma longa negociação (1919-1933) com o patronato com vista ao estabelecimento de um contrato colectivo. Dando razão aos jornalistas, o legislador obrigou as partes, pela lei de 1935, a assumir paritariamente a sua realidade comum, sob o patrocínio do Estado.

A intervenção estatal pode também ser alterada por estratégias políticas: em França, no século XIX, o apoio do Estado na reconstituição da corporação médica procedia da necessidade de, por um lado, melhorar o sistema de saúde e, por outro, delimitar o domínio do clero. A venalidade da imprensa (Jeanneney, 1975), os riscos políticos que esse jornalismo fazia incorrer a um regime parlamentar enfraquecido, os efeitos económicos de práticas duvidosas pesaram na decisão de activar a via parlamentar. O deputado Henri Guernut, autor da proposta de lei de 1933 (da qual resultaria o texto final de 1935), presidia, no momento da votação do seu projecto pela Comissão de Trabalho da Câmara, à Comissão de Inquérito Parlamentar que estava a tratar do caso Stavisky.

Tomar em linha de conta a historicidade deve permitir fazer emergir o carácter sequencial da construção dos grupos. Imagina-se que o desenvolvimento de um grupo não se faz de forma linear, mas por etapas, às vezes com recuos, hesitações que resultam de tensões e conflitos; é preciso também subir patamares que são etapas impostas por constrangimentos externos (económicos, tecnológicos, políticos), mas que podem ser também preliminares que garantem a continuidade do percurso. Parece-nos que o princípio da fronteira pode ser utilizado pela sociologia dos grupos profissionais, nomeadamente pelo do jornalismo.

Em países que não se encontram constrangidos por um crescimento internalisado, as fronteiras - falamos também de postos avançados - são lugares de eleição dos membros sociais que não encontram em espaços antigos (estruturados e até mesmo paralisados) condições de vida ou respostas às suas ambições (Lena Aubertin, 1986). Enquanto todos os espaços não forem apropriados, enquanto existir lugar para os que chegam, a fronteira não se fecha e a diferenciação social permanece enfraquecida. Quando a fronteira se define, quando a concorrência já não puder ser asfixiada pela disponibilidade de territórios ainda "virgens", as lógicas de diferenciação social - nomeadamente de apropriação - começam a concretizar-se. Assiste-se, então, à concentração de recursos e de meios de trabalho, à exclusão, à marginalização ou à alienação de certos membros sociais.

Aplicado a novas profissões ou às que conhecem uma etapa decisiva de desenvolvimento, o conceito de fronteira permite sublinhar as etapas e apostas da estruturação de grupos profissionais. Poderíamos, assim, descrever a história do jornalismo em quatro etapas:

1 - Antes do princípio da imprensa industrial (por volta de 1860), o jornalismo é uma ocupação mal definida e, para além disso, marginal. O jornalismo é um território virgem no essencial: extremamente heterogéneos, os que praticam este ofício são pouco numerosos, porquanto o mercado de trabalho ainda não existe verdadeiramente. Três tipos de profissionais têm já alguma existência: os directores, verdadeiros faz-tudo ("hommes-orchestre") do jornalismo nascente; os copistas, homens polivalentes dos 
primeiros jornais; e os informadores, homens todo-o-terreno do embrionário mercado da informação. Algumas centenas de indivíduos, no máximo, vivem desta actividade.

2 - Este mercado de trabalho vai desenvolver-se graças a uma conjugação de factores (Palmer, 1983) políticos (democratização), económicos (industrialização), culturais (instrução, educação), dando origem ao nascimento da imprensa popular de massas. Vai expandir-se aí, em condições materiais, jurídicas e morais muito variadas, um número crescente de trabalhadores jornalistas que, de maneira permanente ou não, regular ou não, vão fazer emergir do jornalismo os recursos (materiais e simbólicos) necessários à sua existência. Neste período de expansão da fronteira, que se estende até à I Guerra Mundial, encontramos no jornalismo perfis muito variados que podemos classificar em três categorias: a) aqueles para quem o jornalismo é um recurso e uma identidade social secundários: tipógrafos, fotógrafos, secretários de câmara, professores, comerciantes, funcionários... enfim, uma fauna de pessoas que fazem do jornalismo um complemento (financeiro e simbólico, para o qual alguns trabalham mesmo gratuitamente); b) aqueles para quem o jornalismo é a principal ou até mesmo exclusiva ocupação: os articulistas, repórteres, secretárias de redacção, cronistas, directores, fotógrafos... que, em número crescente, fazem do jornalismo a sua principal actividade; c) aqueles que têm uma actividade dupla: advogados, escritores, políticos que apresentam a particularidade de desenvolver uma actividade que se exprime, entre outros lugares, nos jornais.

3 - A guerra de 1914-1918 provocou uma grave crise económica no jornalismo; é também a partir desta altura que a imprensa diária inicia o seu lento declínio. O espaço torna-se mais diminuto e o preço da publicidade aumenta, começando, então, os processos de diferenciação social: a concorrência estrutura argumentos de exclusão, de marginalização, de alienação; uma parte dos membros do grupo inicial, percepcionando-se como "profissionais", procura organizar de outra maneira, e em seu proveito, o espaço de trabalho. Esta fase é também marcada pela criação, em 1918, de uma organização muito activa (o Sindicato Nacional dos Jornalistas) e completa-se em 1935, com a lei sobre o estatuto do "jornalista profissional".

4 - O período seguinte, de 1935 até aos nossos dias, é de concretização das disposições legislativas e regulamentares que rematam a regulação da fronteira, fazendo disso um território antigo, ou seja, estruturado e fechado.

Este corte sequencial é evidentemente artificial, como o é toda a representação da história através das épocas e das rupturas. Haverá, apesar disso, o mérito de organizar o estudo evitando que as diferenças e as evoluções sejam diluídas pela ausência de definição de um espaço de tempo ou, então, que estas estejam excessivamente ligadas a acontecimentos fortes, restritivos do ponto de vista do tempo efectivo, mas importantes nas consequências. Uma determinada lei, uma determinada decisão, uma determinada situação têm raízes na longa duração que importa trazer à luz do dia, sem que para tal se tenha de fazer remontar tudo à noite dos tempos.

Os períodos da história não são equivalentes, tanto pela importância das evoluções que neles se produzem como pelas recordações que deixam atrás de si. Alguns constituem a passagem de um estado latente ou marginal a um estado explícito e po- 
dem representar, de facto, uma "idade de ouro", uma referência nas lutas futuras que incidem sobre a identidade. Para o jornalismo, o período essencial da respectiva construção é incontestavelmente o que se situa entre as duas guerras. Se pensarmos, tal como Michael Palmer sobejamente demonstrou, que a segunda metade do século XIX foi o teatro da invenção das concepções modernas da informação do qual a sociedade actual é herdeira, se podemos acreditar que a conjugação de factores económicos, políticos, culturais e tecnológicos permitiu uma revolução dos usos da imprensa e dos media, devemos ver neste período que vai de 1860 a 1914 o fermento de uma outra evolução importante: a construção de uma representação e de uma organização do jornalismo no seio de um "grupo profissional", as quais vão ser incarnadas por um conjunto de indivíduos e por uma organização sindical numa fase que se situa entre 1918 e 1940. Todos os acontecimentos que se produziram então estavam em embrião no período antecedente: no crescimento do efectivo de jornalistas devido à industrialização; na emergência de um tecido associativo denso, bem descrito, aliás, por Marc Martin (1986) ; nos primeiros contactos internacionais; na visibilidade e na importância social cada vez maior do jornalismo de informação (a fama da reportagem e das entrevistas). Tudo indicava que uma profissão tomava uma forma bem mais definida e que um grupo de indivíduos iria reivindicar isso, passaria a pensar-se como "profissionais”, partícipes do processo e com direito a essa emergência.

O propósito das nossas investigações é precisamente sublinhar as condições desta emergência, desta transformação em grupo visível, que se qualifica como profissional, de um agregado de indivíduos até aí atomizados cuja imagem social não aspirava à unidade. Focalizando a nossa atenção no período entre 1918 e 1940, interessamo-nos por um momento particular no decurso do qual a actividade deixa de ser o lugar de um ou vários grupos fluidos e mal definidos para se tornar num privilégio de um agregado finito, de um grupo claramente identificado e reconhecido.

\section{Representação}

A propósito da "génese das classes" no espaço social, Pierre Bourdieu (1984) sublinha a importância do trabalho de representação ao qual os indivíduos e os grupos se entregam para impor uma visão do mundo e uma concepção da sua própria posição neste mundo social. No decurso das lutas, o trabalho de categorização, de explicitação e de classificação será permanente, sendo que a capacidade para exprimir o conhecimento no estado latente representa um poder considerável que os indivíduos vão tentar controlar: "Na luta pela imposição da visão legítima do mundo social, em que a ciência ela própria está inevitavelmente envolvida, os actores detêm um poder que é proporcional ao seu capital simbólico, ou seja, ao conhecimento que recebem de um grupo", capital que é o produto de lutas anteriores e que pode ser concretizado a todo o momento para defender os interesses do grupo.

É a partir da observação das modalidades transferidas da luta para a construção da categoria (conflitos, negociações, resoluções), do processo pelo qual os actores tornaram enunciável uma categorização (ou uma nova concepção da categorização), da 
acção de monopólio da representação, que retiraremos uma análise renovada dos princípios geradores do grupo profissional contemporâneo. Este ponto essencial foi sublinhado por C. Paradeise (1988): “Cada traço é susceptível de caracterizar uma profissão quer como produto quer como condição de trabalho de produção e de reprodução da profissão, tal como ocorre com outros recursos e constrangimentos de acção à volta de uma aposta central: a monopolização de um segmento de mercado de trabalho que visa dominar a incerteza da relação salarial ou de mercado".

A construção do grupo profissional dos jornalistas no período que decorre entre as duas guerras está indissociavelmente ligada a uma organização, o Sindicato dos Jornalistas, nascido em 1918, ascendendo ao estatuto de "nacional" em 1928, e com uma progressão fulminante - a palavra não é demasiado forte para um contexto tão dilacerado ("éclaté"): festejando o seu milésimo membro em 1925, o seu efectivo total é de 2751 sindicalizados em 1939 e destes mais de dois terços eram jornalistas profissionais (dado que correspondiam aos critérios da lei).

Se bem que seja necessário perceber, no decurso deste período, a heterogeneidade dos actores e das estruturas que concorrem para a profissionalização do grupo (um primeiro sindicato de jornalistas, inspirado pelo movimento operário, havia sido criado em 1905; por outro lado, as grandes associações desempenham um papel essencial na passagem do século), a influência do SNJ marcou profundamente a identidade do grupo. Importa ver nas estruturas actuais o traço não só das concepções, mas também das estratégias que foram vencedoras e validaram com o mesmo vigor uma visão do jornalismo no espaço social. O corporativismo do grupo (de que falaremos mais à frente) tem a sua origem - pelo menos em parte - na estratégia unitária do Sindicato, inspirado pelo sindicalismo britânico, que constituía uma originalidade para a época (há quem calcule que o número das associações, mútuas e sociedades de jornalistas ultrapassava, em 1930, as 150 - Barc, 1935) cuja eficácia era bem visível: persistente, organizado, coerente, o SNJ obteve numerosos benefícios sociais, constituindo a lei de 1935 o seu remate; soube também defender permanentemente os seus membros em momentos de conflitos laborais e fez isso tantas vezes e tão bem que se pode vangloriar de ter proporcionado aos seus membros mais dinheiro do que aquele que thes solicitou: comparando as cotizações sindicais reclamadas e as somas recebidas pelos associados como forma de regular litígios que o Sindicato acompanhou, estima-se precisamente que em dez anos (1925-1935) recuperou 113\% das cotizações pagas pelo conjunto dos seus associados. Recusando todas as formas de confederalismo, sejam elas de ramo ou sector (o SNJ abandonou a Confederação dos Trabalhadores Intelectuais, bem como o Comité Geral das Associações de Imprensa, depois de ter integrado as suas estruturas, durante algum tempo, por puro oportunismo estratégico) ou universalistas (por três vezes, o Sindicato recusou a adesão à CGT), o SNJ não deixou de provar a eficácia da sua estratégia corporativa e soube convencer a comunidade acerca disso.

Outra concepção que nos parece provir da estratégia sindical foi o privilégio dado às formas "profissionais" do jornalismo, uma distinção que se encontra no centro da lei (que define o estatuto dos "jornalistas profissionais", distinguindo-o implicitamente de outras formas, não definidas). A análise do discurso da organização sindi- 
cal, ao longo de duas décadas, leva a pensar que, no "mercado" de clientela, o SNJ escolheu deliberadamente posicionar-se num patamar bem específico. Enquanto certas organizações estavam constituídas sobre bases de afinidades políticas (republicanas, socialistas, católicas, cristãs...), de lógicas regionais (parisienses, departamentais...) ou de especialidades (desportivas, hípicas, judiciais, militares...); enquanto algumas delas admitiam no seu seio jornalistas como directores; enquanto que todas não eram mais do que clubes de reunião ou organismos de previdência, o SNJ apresentou-se como um sindicato unitário, sem orientação política e vocacionado para a defesa dos interesses dos trabalhadores. Enquanto que as organizações anteriores não distinguiam grandes diferenças entre os jornalistas a tempo inteiro e os diletantes, entre aqueles que faziam do jornalismo um complemento ou prolongamento e aqueles que encaravam esse trabalho como a sua principal actividade, o SNJ vai seleccionar os seus membros através de um argumento simples: o jornalismo deve ser para "jornalistas autênticos".

O seu discurso a propósito da definição do jornalismo torna-se mais radical no decorrer dos anos 20 do século passado, procurando fazer entrar nesse conceito apenas aqueles que fazem do jornalismo a sua única ou principal ocupação. Chega mesmo a impor esta definição restritiva e tautológica à lei, já que esta abandona a proposta mais vaga e menos rígida que tendia a outorgar o estatuto a todos aqueles que tinham na imprensa uma colaboração intelectual ou artística. O jornalismo contemporâneo não seria o que é se não tivesse sido assim modelado pela estratégia de uma organização que construiu o grupo tanto como foi construída por ele.

Entrevistas que efectuámos junto de jornalistas de títulos municipais ${ }^{1}$ e de correspondentes de imprensa local ${ }^{2}$ sublinham como esta visão de um jornalismo profissional - o único em conformidade com as normas - pode ser partilhada, integrada e reproduzida por aqueles que são daí excluídos, ainda que a observação e análise de tarefas concretas incitem a pensar o contrário. Como outrora, podemos fazer jornalismo, sem sermos jornalistas. Hoje, jornalistas de redacções centrais e correspondentes locais consideram frequentemente que são jornalistas no acto e não na alma: dizem que fazem jornalismo, mas que não se representam como jornalistas, alguns afirmam que essa distinção lhes parece necessária, reproduzindo, desse modo, a visão de um “jornalista profissional” acima de toda a confusão.

\section{Corporativismo}

Os grupos não se movem apenas por estratégias orientadas no sentido da apropriação da representação e do poder; existem também em função de necessidades da vida material, nomeadamente de sobrevivência (a actividade laboral que participa da identidade individual e colectiva procura, antes de tudo, bens materiais); a constituição de classes responde a necessidades de apropriação e de conservação de espaços económicos;

\footnotetext{
${ }^{1}$ Inquérito aos redactores e responsáveis de jornais locais da região oeste da França. Resultados publicados em Médiaspouvoirs, $\mathrm{n} .^{\circ}$ 35, terceiro trimestre de 1994.

${ }^{2}$ Inquérito aos correspondentes de um semanário de informação local da região oeste da França. Resultados inéditos, 1996.
} 
a contribuição dos indivíduos para a construção de uma visão do espaço social cujo objecto é a representação diferenciada - hierarquizada - do mundo social tem - também - como intenção final a apropriação - e a respectiva justificação - de um segmento do mercado de trabalho.

É provável que, em França, a consideração das problemáticas profissionais, já fecunda nos Estados Unidos desde 1970, tenha sido retardada por um certo tabu relacionado com a noção e a realidade da organização corporativa de certos sectores do trabalho, e mais globalmente com a organização de grupos profissionais. Podemos ver aí o sinal de um passado mal assumido, o do Governo de Vichy que, através da "Charte du Travail”, instituía uma "organização social de profissões” que constituía um regresso aos funcionamentos corporativos do Antigo Regime (a Revolução colocaria fim ao sistema de corporações). Este período ainda recente, que não é estranho ao recrudescimento do fascismo na Europa (Itália, Alemanha, Portugal, Espanha, França), contribui para reforçar o que D. Segrestin (1992) chama um "tabu comunitário", que pretendia que "não houvesse nada entre o indivíduo ligado pelo contrato de trabalho e o colectivo representado pelo sindicato".

Qualquer forma de organização profissional e, consequentemente, qualquer estudo a partir de paradigmas profissionalistas foram, durante muito tempo, considerados como um ataque às formas sindicais de defesa dos interesses dos trabalhadores. No entanto, como o demonstraram os trabalhos de Segrestin (1986), o fenómeno corporativo está longe de ter desaparecido em França. As corporações, desde as origens até à sua interdição, constituíram um sistema de gestão do mercado de trabalho. Este permitia regular o acesso ao trabalho, garantir aos seus membros uma forma de protecção, integrar os jovens e reservar a um número limitado de pessoas o benefício de uma actividade (Cotta, 1984).

Tolerado e depois encorajado pela feudalidade, contestado por Colbert e proibido por Turgot, o sistema corporativo encontrava-se em decomposição em 1789: minado por conflitos entre patrões e operários (os primeiros tendo excluído da solidariedade corporativa os segundos), dá lugar a incessantes batalhas entre comunidades de ofícios para a instituição de privilégios e monopólios. Este duplo conflito envolvia um conservadorismo tecnológico e económico. O sistema corporativo gerou o corporativismo e os seus efeitos.

No decurso do século XIX, o modo corporativo não desapareceu, particularmente em França onde, aliás, esteve mais presente. Comparando os movimentos de profissionalização em Inglaterra e nos Estados Unidos do início do século XIX até aos nossos dias, Magali Sarfatti-Larson (1997) assinala que a análise de diversos projectos profissionais sugere que eles visavam criar um mercado institucional protegido de trabalho ou de serviços para indivíduos cuja competência devia também ser institucionalmente demonstrável. Catherine Paradeise (1988) sublinha igualmente a persistência de estratégias monopolistas, sejam elas legais, contratuais ou factuais, a revolução liberal que pretendia libertar a força do trabalho dos constrangimentos sociais e entregá-la ao mercado, não tendo nunca impedido totalmente a acção das antigas corporações, dos Estados, das empresas e dos sindicatos universalistas. 
Esta persistência guiou um certo número de investigações recentes a propósito de profissões fechadas (marinha mercante, estivadores, ferroviários, médicos, impressores...) que sublinham a ambivalência fundamental da intenção corporativa.

\section{Dualismo}

A atitude corporativista não apresenta apenas conotações negativas e a sua persistência deve conduzir a reconhecer os seus aspectos positivos. Pertencer a uma comunidade de ofício oferece aos respectivos membros recursos psicológicos e sociológicos: "Comunidade de referência necessária à formação da consciência individual e colectiva, ela é, por extensão, um aspecto positivo do sistema social, porquanto o movimento operário de longa data se organizou para promover a acção e a mudança”, sustenta Segrestin (1985).

Este dado positivo explica por que, em finais do século XIX, o modo corporativo se encontra novamente em debate e o corporativismo tenha sido reabilitado. Émile Durkheim (1883) referiu-se assim a esta questão: “Uma nação apenas se pode manter se, entre o Estado e os particulares, se intercalar uma série de grupos secundários que estejam suficientemente próximos dos indivíduos para os atrair fortemente para a sua esfera de acção e os envolver, desse modo, na torrente geral da vida social (....) Os grupos profissionais não estão aptos a cumprir esse papel, como se orientam para isso". Apresentando-se como uma alternativa tanto ao liberalismo como ao socialismo, encontrando os seus ideólogos, o corporativismo teve, há um século, uma audiência que ia muito para além da direita reaccionária, meio político ao qual geralmente é associado. A reflexão sobre a identidade dos grupos profissionais e suas estratégias tem mais heranças disso do que aquilo que julgamos.

O jornalismo oferece um terreno de estudo da persistência da atitude corporativista, ao mesmo tempo que sublinha a sua ambivalência. O processo de profissionalização que os jornalistas encetaram desde o século XIX e que fizeram acelerar no período entre as duas guerras teve por objectivo constituir os jornalistas num grupo coerente, estruturado e, desse modo, capaz de proteger os interesses dos seus membros, tanto do ponto de vista material como simbólico. A história do grupo jornalístico é a ilustração perfeita do benefício (socialização, protecção, identidade) que os trabalhadores podem retirar de um processo corporativo que consistiu em fechar o território profissional, em reservá-lo a uma categoria especial de membros em detrimento de outros que se viram, assim, excluídos.

Mas esta história mostra também como uma tal concepção de essência corporativista pode levar a criar e a perpetuar injustiças, a legitimar a concretização de disposições duais do mercado de trabalho em nome de uma regulação racional e justa da disponibilidade de emprego e também em nome de uma defesa da causa dos trabalhadores face ao patronato. Encontra-se aqui a situação singular dos correspondentes da imprensa local, cujo exemplo invocámos.

Preocupado em afirmar o carácter profissional do jornalismo concebido como autêntico e legítimo, o Sindicato lançou, desde a sua criação, o anátema sobre os diferen- 
tes concorrentes, como funcionários, políticos e correspondentes de província: comerciantes, professores, livreiros, funcionários municipais, reformados que colaboravam com a imprensa em graus diversos de importância, mas cuja ajuda era preciosa. Lançou mesmo contra eles uma campanha de denúncia (1930), aludindo a "intrusos" que "pululavam", sublinhando que os jornalistas tinham deixado de estar dispostos "a tolerar" e afirmando que esses empregos eram "desenvolvidos por amadores trabalhando ao desbarato". A lei será explicitamente dirigida contra eles, sendo, desse modo, excluídos dos benefícios dessa profissão.

No entanto, desde 1937, o SNJ reconhecia que a lei havia criado um espinhoso problema. Com efeito, a imprensa local retirava o seu sucesso da malha fina da informação de proximidade, graças à colaboração de correspondentes locais não "profissionais" face à lei e o sindicato deixava de ver como e porquê impedir uma tal realidade. Seria, então, necessário regressar ao princípio da lei e conferir estatuto a pessoas pouco tempo antes votadas à vindicta profissional? "Para perceber a gravidade do problema”, acrescentava, lúcido, o Sindicato, "diremos que entre o trabalho do funcionário municipal que é correspondente do jornal nos seus momentos livres e o do redactor (num escritório isolado ou numa redacção local) integralmente profissional, não existe uma diferença de natureza, mas de volume... e de valor".

O Sindicato reconhecia que a obtenção do estatuto fora realizada nas costas de trabalhadores que, afinal, eram respeitáveis e agora legalmente sobre-explorados pelos jornais, sendo que os correspondentes ganhavam consideravelmente menos do que os jornalistas e, além disso, estavam circunscritos a um estatuto "liberal” que não conferia qualquer protecção (direitos sociais, emprego...). A isso tinham escapado os jornalistas pela lei de 1935. O SNJ admitia que um sistema dual, já existente, fora reforçado pela sua acção e respectivos resultados.

No entanto, 60 anos depois, a situação é a mesma: um exército de 33 mil correspondentes da imprensa local (número que se pode confrontar com os seis mil jornalistas da imprensa regional) constitui perto de 80 por cento da massa redactorial dos jornais, fazendo reportagens, síntese de informações e fotografias, escrevendo artigos e recebendo, para isso, honorários (e não salários), sendo quatro ou cinco vezes menos dispendiosos do que os assalariados, mas não tendo qualquer protecção. Uma lei recente veio confirmar este subestatuto através de uma definição cheia de ambiguidades: "O correspondente local da imprensa departamental e regional contribui, de acordo com o desenvolvimento da actualidade, para a recolha da informação de proximidade relativa a uma zona geográfica determinada ou para uma actividade social particular por conta de uma empresa editora. Trata-se de uma parte de informações submetida, antes de uma eventual publicação, à verificação ou reescrita por um jornalista profissional”.

\section{Competência e qualificação}

Se a construção das profissões passa por um esforço de elaboração, de representação, a competência adquire aí um lugar preponderante. Desenvolvendo um estudo sobre a marinha mercante, C. Paradeise (1984) demonstrou o lugar primordial da forma- 
ção na estruturação de certos mercados de trabalho fechados cujo objectivo é proteger os trabalhadores que empregam face à concorrência externa e interna.

A pertinência desta análise é limitada aos mercados muito estruturados, como o da marinha mercante. Mas ela pode ser estendida ao conjunto dos grupos profissionais, desde o momento em que é definida uma modalidade mínima de fechamento que restrinja o acesso aos empregos. Esta modalidade comum não é forçosamente um diploma, um título, um traço distintivo, um curso, uma antiguidade, mas uma qualificação, ou seja, “o produto de um acordo estabilizado, incidindo sobre a relação entre as potencialidades reconhecidas à força do trabalho e as tarefas que lhes são atribuídas. O reconhecimento desta relação deriva ela própria, de uma forma ou de outra, de uma relação de força entre as partes que estão integradas nessa construção" (Paradeise, 1988).

A criação do monopólio de trabalho ou o reconhecimento de uma influência decisiva (já que as situações realmente exclusivas são mais raras) dependem da construção de uma competência específica e do respectivo reconhecimento. Esta construção necessita do acordo ou da coacção das partes interessadas pela relação de trabalho: os trabalhadores, os empregadores, os poderes públicos e, em certos casos, os utentes. As modalidades de fechamento do mercado de trabalho, quer seja total ou parcial, são explícitas ou implícitas: às vezes é a lei; frequentemente são os costumes; em muitos casos é o contrato colectivo.

Se o fechamento está intimamente regido pelo estabelecimento da "qualificação", numerosos exemplos demonstram que esta não se sobrepõe às tarefas de trabalho, nomeadamente por causa do dualismo anteriormente apontado e das divergências importantes que podem aparecer entre a invocação das tarefas e a actividade realmente efectuada.

J.-D. Reynaud (1987) define a qualificação como uma regulação conjunta de regras implícitas ou explícitas, resultado da combinação de estratégias patronais e salariais respeitantes à organização de um mercado de trabalho específico (acesso e segurança de emprego, carreiras, formação, diplomas), na qual o Estado participa em diferentes graus; esta regulação está ligada a um tipo de organização da produção, sendo aí um elemento de estruturação; é igualmente o produto de um mercado interno de trabalho (promoções, disponibilidade e controlo de empregos); enfim, está fortemente dependente de uma cultura profissional, específica a cada grupo.

Esta regulação conjunta da qualificação, entendida como acordo entre as potencialidades da força de trabalho e as tarefas, está intimamente ligada à representação que os actores fazem da sua identidade e daquela que lhes é atribuída por outrem. A ideia que uns e outros fazem da sua competência interfere tanto na construção da qualificação como nas modalidades de regulação conjunta.

Este estado de regulação é produzido pelo estado de divergências internas de cada parceiro, porque as representações, por natureza instáveis, constituem um campo privilegiado de afrontamentos. Se "a institucionalização reforça os traços distintivos, levando-os para a consciência dos agentes”, como afirma Boltansky (1982), também é ocasião de lutas entre facções, grupos e subgrupos rivais para a mobilização de forças sociais, lutas que não se desenrolam apenas no plano material, mas também na ordem simbólica. A regulação é também o resultado do choque de argumentos de facções que 
se degladiam na base de modelos de identificação, com o objectivo de controlar os destinos da sua "comunidade de trabalho". É, por isso, tributária de estados contingentes que modelam a qualificação.

A reprodução do fechamento dos mercados de trabalho tem a ver com a capacidade de resposta da qualificação face às tarefas de produção. Ora, as necessidades, as tecnologias, os valores evoluem e a qualificação tende a ficar inadaptada. Os grupos para os quais a regulação se constrói num nível implícito beneficiam da flexibilidade, que pode ser reforçada pela coesão e a solidez dos fundamentos da comunidade. Certos grupos deram lugar a dispositivos jurídicos, que os protegem em particular da concorrência, mas que podem revelar-se pesados em caso de inadaptação da qualificação às evoluções. Aí, encontra-se cada vez mais presente um nível implícito de regulação, em contradição mais ou menos profunda com os termos explícitos da lei.

A observação do jornalismo permite confirmar a ideia de que a competência não é uma questão absoluta, mas um ajustamento que resulta de uma negociação. Falámos, noutros trabalhos, do carácter fluido da competência jornalística e colocámos em causa a pretensão de um saber técnico autónomo. Se essa fluidez é real, ela parece-nos produto do interesse partilhado de empregados e empregadores que encontram uma vantagem comum na imprecisão. O benefício é mais simbólico do que material: a aura do jornalismo encontra-se reforçada pela largura do espectro das suas competências possíveis, a extensão do seu perfil facilita a sua adaptação às evoluções tecnológicas e económicas, a envergadura do seu território de geometria variável permite gerar antagonismos que derivam das mudanças.

Conservando um princípio genérico, o trabalho do jornalismo renovou-se consideravelmente desde há um século. O que há de comum entre aquele que escrevia crónicas com uma caneta e o jornalista-repórter-editor de imagem de televisão ou entre o secretário de edição que assegura a expedição pelo caminho-de-ferro de encomendas de cópia a imprimir e a $\mathrm{PAO}^{3}$ ? Quantas evoluções a competência teve de concretizar para dar origem a esses jornalistas que produzem informação a partir de bases de dados "on line"?

Todas essas mudanças deram lugar a uma negociação permanente que consiste em redefinir a competência (como produto de um acordo entre as partes) a fim de manter o fechamento do território e assegurar a reprodução do grupo profissional. A história do jornalismo deixa, aliás, um rasto precioso deste ajustamento por pequenos passos: os debates e decisões da Comissão da Carteira dos Jornalistas Profissionais (CCIJP), instituída pela lei de 1935, marcam, de há 60 anos até hoje, o percurso da qualificação.

Desde o início dos seus trabalhos em 1936, a Comissão teve de se pronunciar sobre o estatuto de perfis profissionais particulares: os fotógrafos, os repórteres de actualidades cinematográficas, os cenógrafos, os repórteres e apresentadores de rádio e mais tarde os jornalistas de televisão, enfim os redactores de jornais municipais, ultimamente os infográficos... inúmeras vezes, a CCIJP, uma comissão paritária de jornalistas e dirigentes de empresas jornalísticas, teve de retomar o trabalho da qualificação do jornalismo, arbitrando os dossiers dos “casos-limite"(Da Lage, 1995), perfis

${ }^{3}$ N.T.: PAO - Publication Assistée par Ordinateur. 
profissionais particulares, porque eram mais híbridos do que o habitual e poder--seiam amalgamar de forma não ponderada. Chamando à colação a jurisprudência, os candidatos levavam a sua exigência até aos tribunais administrativos e ao Conselho de Estado. A competência do jornalismo constitui o terreno de um debate constante e rico que vai globalmente no sentido da abertura, mesmo quando patrões e jornalistas se aliam para manterem uma definição mais apertada. Em 30 anos, o número de jornalistas multiplicou-se por $2,8^{4}$ e o espectro da sua qualificação não parou de crescer, sem que o grupo tenha sido afectado nas bases.

O exemplo do jornalismo demonstra também que a qualificação (elemento de objectivação e de reprodução do fechamento) não é sinónimo de formação: a parte relativa dos diplomas das escolas de jornalismo decresce; em 1973 eram 20\% contra 14,8\% em 1990 (incluindo aqui os licenciados das escolas não reconhecidas paritariamente pela profissão) e esta tendência acentua-se actualmente, provando que a negociação da qualificação (como acordo entre as potencialidades da força e das tarefas) pode efectuar-se independentemente dos quadros organizados de reprodução.

O jornalismo faz ressaltar a ideia de que a competência (como produto de um acordo estabilizado entre patrão e trabalhadores) pode comportar uma cláusula dual: a convenção pode admitir - no caso, de forma implícita - uma distribuição da competência sobre a força do trabalho entre um centro (com o qual o pacto é firmado formalmente) e uma periferia, ao mesmo tempo excluída do principal dos benefícios do acordo e aceite para trocar a sua força de trabalho por uma retribuição (material e simbólica) desfavorável. O dualismo é consubstancial à concordância em torno da competência; se esta dimensão do acordo não existisse, este deveria ser estabelecido de outra forma, certamente menos favorável para as partes.

Este dualismo inseparável da competência sublinha a vivacidade do fenómeno corporativo. Se existe, a corporação jornalística é decerto diferente da concepção do Antigo Regime, que foi reactivada pelos governos fascistas: não há aí integração vertical completa. Esta foi rompida no início do século XX, com a criação do SNJ e o declínio correlativo das associações mistas. No entanto, é pertinente que nos perguntemos se a corporação não encontra uma nova expressão numa hierarquia vertical a três níveis: a elite (do audiovisual e dos grandes jornais parisienses cuja pregnância foi sublinhada por R. Rieffel - 1984); a massa legítima (constituída por aqueles que têm direito ao estatuto, em rápida expansão nos últimos anos); e a margem (todos os que participam sem serem reconhecidos de forma igual, subgrupo de configuração indefinida cuja definição varia conforme o grau de aceitação). Entre estes níveis, os efeitos do corporativismo são assinaláveis. Traduzem-se no conservadorismo que gera qualquer estrutura deste tipo, assim como nas formas de sociabilidade e de solidariedade, que se observam em momentos em que o corpo social põe em causa o grupo, provocando o cerrar de fileiras da "grande família".

(Tradução de Felisbela Lopes)

${ }^{4} 10000 \mathrm{em} \mathrm{1965,} 28000 \mathrm{em} 1995$. 


\section{Bibliografia}

Barc, L.-M. (1935). Le délai-congé des journalistes, tese de Direito, Rennes.

Baszanger, I. (1990). 'Émergence d'un groupe professionnel et travail de légitimation: Le cas des médecins de la douleur', Revue française de sociologie, vol. XXXI.

Becker, H. (1988). Les mondes de l'art, Flammarion.

Boltanski, L. (1982). Les cadres, la formation d'un groupe social, Éditions de Minuit.

Bourdieu, P. (1984). 'Espace social et genèse des classes', Actes de la recherche en sciences sociales, n. ${ }^{\circ} 52-53$.

Bucher, R. \& Strauss, A. (1961). 'Profession in process', American journal of sociology, n. ${ }^{\circ} 46$.

Cotta, A. (1984). Le corporatisme, PUF.

Da Lage, O. (1995). 'Les critères de professionnalisme de la Commission de la carte d'identité des journalistes professionnels', Mathien, M. \& Rieffel, R. (Dir.), L'identité professionnelle des journalistes, Actes de colloque, Alphacom-CUEJ, Strasbourg.

Delporte, C. (1995). 'Les journalistes dans l'entre-deux-guerres, une identité en crise', Vingtième siècle.

Derosières, A. \& Thévenot, L. (1988). Les catégories socio-professionnelles, La Découverte.

Dubar, C. (1992). La socialisation: Construction des identités sociales et professionnelles, A. Colin.

Durkheim, É. (1883). Division du travail, tese. Paris.

Hughes, E. (1971). The sociological eye, Aldine.

Jeanneney, J.-N. (1975). 'Sur la vénalité du journalisme financier entre les deux guerres', Revue française de sciences politiques, Agosto.

Lacan, J.-F.; Palmer, M. \& Ruellan, D. (1994). Les Journalistes - Stars, scribes et scribouillards, Paris: Syros éditeur.

Lévêque, S. (1996). La construction journalistique d'une catégorie du débat public, tese de doutoramento, Universidade de Paris I.

Léna, P.; Aubertin, C. et al. (1986). 'Frontières, mythes et pratiques', Cabiers des sciences humaines, ORSTOM, Paris.

Lucas, Y. \& Dubar, C. (eds.) (1994). Genèse et dynamique des groupes professionnels, Presses universitaires de Lille.

Martin, M. (1986). 'La grande famille: l'Association des journalistes parisiens (1885-1939)', Revue historique, vol. CCLXXV-1, Janeiro-Março.

Martin, M. (1991-1992). Contribution à l'histoire des journalistes et du journalisme en France (XIXeXXe siècles) et à l'histoire de la publicité en France, tese em curso, Universidade de Paris X, Nanterre.

Mercier, A. (1994). 'L'institutionnalisation de la profession de journaliste', Hermès, 13-14.

Palmer, M. (1983). Des petits journaux aux grandes agences - Naissance du journalisme moderne - 1863/ 1914, Paris: Aubier.

Paradeise, C. (1988). 'Les professions comme marchés de travail fermés', Sociologie et sociétés, vol. XX, n. ${ }^{\circ} 2$, Outubro.

Paradeise, C. (1984). 'La marine marchande française : un marché de travail fermé?', Revue française de sociologie, vol. XXV.

Primon, J.-L. (1994). 'Une profession en train de se faire: les formateurs', in Lucas, Y.; Dubar, C. (dir.) Genèse et dynamique des groupes, Presses universitaires de Lille.

Reynaud, J.-D. (1987). 'Qualification et marché du travail', Sociologie du travail, 1.

Rieffel, R. (1984). L'élite des journalistes, PUF.

Ruellan, D. (1993). Le professionnalisme du flou - Identité et savoir faire des journalistes français, Grenoble: PUG.

Sarfatti-Larson, M. (1977). The Rise of the professionalism, University of California Press.

Sarfatti-Larson, M. (1988). 'A propos des professionnels et des experts ou comme il est peu utile de tout dire', Sociologie et sociétés, vol. XX, n. ${ }^{\circ} 2$, Outubro.

Segrestin, D. (1985). Le phénomène corporatiste: essai sur l'avenir des systèmes professionnels fermés en France, Fayard.

Segrestin, D. (1992). Sociologie de l'entreprise, A. Colin. 
Weiss, J. (1984). 'Bridges and Barriers: Narrowing Access and Changing Structure in the French Engineering Profession', in Geison, G. (ed.), Professions and French State, 1700/1900, Filadélfia: University of Pennsylvania Press.

Archives de l'Assemblée nationale, PV des séances de la Commission du travail.

Archives de la Commission de la carte d'identité des journalistes professionnels.

Brachard, É. (1935). Rapport au nom de la Commission du travail n. ${ }^{\circ} 4516$, Chambre des députés.

Bureau international du travail (1932). Rapport de la Commission consultative des travailleurs intellectuels, Genève.

Bureau international du travail (1928). Les conditions de travail et de vie des journalistes.

Guernut, H. (1933). Proposition de loi $n .^{\circ} 1653$, Chambre des députés.

Godart, J. (1935). Rapport au nom de la Commission du commerce, de l'industrie, du travail et des postes n. ${ }^{\circ} 279$.

Revistas Bulletin du Syndicat des journalistes e Le Journaliste, du Syndicat national des journalistes. 